01_Abad Arenas 13/04/2011 12:25 Página 11

\title{
ESTUDIOS
}


01_Abad Arenas 13/04/2011 12:25 Página 12 
ReVISTa de Derecho UNED, núm. 7, 2010

\section{REFLEXIONES SOBRE LOS REQUISITOS Y LAS \\ PROHIBICIONES EXISTENTE PARA PODER ADOPTAR Y SER ADOPTADOS: LA CONCILIACIÓN ENTRE EL CÓDIGO CIVILY LA NORMATIVA DE LAS COMUNIDADES AUTÓNOMAS}

\section{ENCARNACIÓN ABAD ARENAS ${ }^{1}$}

Becaria de Investigación del Departamento de Derecho Civil de la UNED

Resumen: En este artículo se estudiará qué sujetos pueden adoptar y ser adoptados según lo previsto en el Código civil español y la jurisprudencia recaída en la materia. Asimismo en el texto se presta especial atención a la normativa autonómica, teniendo en cuenta que éstas han contemplado las adopciones llevadas a cabo por parejas de hecho del mismo o distinto sexo. Por último, se hará referencia al requisito de la idoneidad, cuyos criterios enunciados en el Código civil, se ven desarrollados por lo disciplinado en dicha normativa autonómica.

Palabras clave: Adopción, Pareja de hecho estable homosexual, Idoneidad.

Abstract: This article aims at the analysis of the following subject: who can adopt, and who can be adopted, according to Spanish Civil Code and the case law related to this matter. Within this text, it is also taken into account the rules enacted by the Spanish non governmental authorities (the so called Comunidades Autónomas). We take make reference of the fact that these "Comunidades Autónomas» had foreseen the adoptions made by unmarried couple (such as homosexual or heterosexual).

Finally, we mention one requirement: the aptitude to adopt. The Spanish Civil Code makes a reference to these criteria, which are also developed in the rules enacted by "Comunidades Autónomas".

\footnotetext{
${ }^{1}$ Licenciada en Derecho y Diploma de Estudios Avanzados en Derecho Civil por la Universidad Nacional de Eduacación a Distancia.
} 
Key bords: Adoption; homosexual unmarried couple; aptitude.

Sumario: I. Planteamiento preliminar.-II. requisitos del adoptante o adoptantes. -1 . Edad mínima y diferencia de edad entre adoptante y adoptando.-2. La capacidad del adoptante: el caso de los adoptantes incapacitados judicialmente.-3. Adopción Conjunta.-4. Adoptantes en la Ley Foral Navarra 6/2000, de 3 de julio.-4. Adopción Sucesiva.-6. Adopción «Post Mortem».-III. Sujetos susceptibles de ser adoptados .-1. Menores no emancipados.-2. ¿Puede ser adoptado el «Nasciturus»?.-3. Los mayores de edad y los menores emancipados como adoptandos: excepcionalidad de esta posibilidad.-4. Sujetos que no pueden ser adoptados: las prohibiciones.-IV. La idoneidad y el procedimiento de adopción: entidades públicas de adopción.-V. Reflexiones conclusivas.-VI. Bibliografía.-VII. Índice de resoluciones

\section{PLANTEAMIENTO PRELIMINAR}

La adopción ha sido objeto en los últimos años de numerosas reformas, hasta quedar redactada en la actualidad como muestran los artículos 175 a 180 del Título VIII «De las relaciones paterno-filiales», del Capítulo V "De la adopción y otras formas de protección de menores», Sección II «De la adopción», del Libro I del Código civil².

\footnotetext{
${ }^{2}$ En la legislación española el proceso de reforma se ha instrumentado, mediante la aprobación de las siguientes leyes: En primer lugar, la Ley 24 de abril de 1958, introdujo la distinción entre adopción plena y menos plena, admitiendo que se pactaran derechos sucesorios en la estructura de la adopción; Posteriormente, la Ley 7/1970, de 4 de julio, de modificación del capítulo V del título VII del libro I del Código Civil, sobre adopción, redujo los requisitos para adoptar, así como estableció las categorías de adopción simple y plena, convirtiendo esta última en la norma. Por otra parte, con las Leyes 11/1981, de 13 de mayo, de modificación del Código Civil en materia de filiación, patria potestad y régimen económico del matrimonio y 30/1981, de 7 de julio, por la que se modifica la regulación del matrimonio en el Código Civil y se determina el procedimiento a seguir en las causas de nulidad, separación y divorcio, se modificaron algunas cuestiones de detalle, emanadas de la nueva concepción del Derecho de familia. A ellas les siguieron: la Ley 21/1987, de 11 de noviembre, de modificación del Código Civil y la Ley de Enjuiciamiento Civil en materia de adopción y otras formas de protección de menores -que con ligeras modificaciones introducidas por la Ley Orgánica 1/1996, de 15 de enero, de Protección Jurídica del menor, de modificación parcial del Código Civil y la ley de Enjuiciamiento Civil-, incorporó el texto articulado vigente del Código Civil; la Ley 13/2005, de 1 de julio, por la que se modifica el Código Civil en materia de derecho a contraer matrimonio, se equipararon los matrimonios homosexuales a los heterosexuales, quedando plenamente legitimados los primeros para adoptar, y, finalmente, la Ley 54/2007, de 28 de diciembre, de adopción in-
} 
REFLEXIONES SOBRE LOS REQUISITOS Y LAS PROHIBICIONES...

En términos generales, podemos avanzar que nuestro Código civil regula un único modelo de adopción -la de efectos plenos-, que aunque inicialmente se encuentra limitada a la adopción de menores de edad, en casos excepcionales prevé su extensión a los mayores de edad y menores emancipados.

Adicionalmente, cabe afirmar que la adopción se configura como un instrumento de integración familiar dirigido con carácter prioritario, a la atención del interés del menor. En esta institución se consagra la completa ruptura del vínculo jurídico que éste mantenía con su familia de origen y la creación de un vínculo de parentesco entre adoptando y adoptante con idénticos efectos a los producidos en la filiación por naturaleza o biológica.

En cuanto a sus presupuestos y por lo que a los elementos subjetivos se refiere, el adoptante podrá ser una persona sola, o una pareja matrimonial o de hecho -de igual o distinto sexo- que quiera adoptar. Por lo que se refiere al adoptado/a, revisaremos la concurrencia de su voluntad, y también analizaremos la concurrencia de otros requisitos de carácter formal para la tramitación del oportuno expediente de adopción.

\section{REQUISITOS DEL ADOPTANTE O ADOPTANTES}

\section{Edad mínima y diferencia de edad entre adoptante y adoptando}

Dice el artículo 175.1 del Código civil, que: «La adopción requiere que el adoptante sea mayor de veinticinco años. En la adopción por ambos cónyuges basta que uno de ellos haya alcanzado dicha edad. En todo caso, el adoptante habrá de tener, por lo menos catorce años más que el adoptado» ${ }^{3}$.

\footnotetext{
ternacional, establece normas relativas al Derecho internacional privado en materia de adopción internacional. En este sentido, LASARTE ÁlvAREz ha llevado a cabo un detallado estudio sobre las sucesivas reformas legislativas sufridas por el instituto de la adopción (Vid., Principios de Derecho Civil IV, Derecho de Familia,

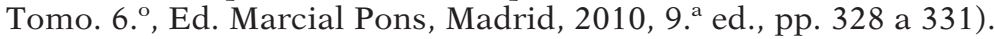

${ }^{3}$ Núm. 1 del artículo 175 redactado por LO 1/1996, de 15 de enero, de Protección Jurídica del Menor, de modificación parcial del Código Civil y la Ley de Enjuiciamiento Civil.
} 
Del tenor literal del precepto cabe deducir que todo aquél que pretenda llevar a cabo una adopción deberá ostentar ciertos requisitos independientes de las circunstancias específicas de cada adopción.

Asimismo, el Código civil parte de una edad mínima establecida en veinticinco años cumplidos, aunque no fija una edad máxima. Esta edad máxima ha sido aplicada por algunas Comunidades Autónomas -en adelante CCAA- lo que ha supuesto una discriminación injustificada, debido a la edad avanzada que en la actualidad presentan muchos padres biológicos ${ }^{4}$.

En este sentido, entre otras, la Comunidad Valenciana, Aragón, Castilla-La Mancha, Cataluña, Murcia y Navarra se remiten a lo establecido en el Código civil, por el contrario, otras Comunidades han establecido una diferencia máxima de edad entre la del adoptante y el adoptado $^{5}$. En la mayoría de los casos, dicha diferencia máxima se fija en cuarenta años ${ }^{6}$, de modo que una persona de cincuenta años sólo podrá adoptar a menores que tenga, como mínimo, diez años de edad.

Asimismo, conviene precisar que el Código civil al no regular con detalle los requisitos que deben concurrir en las personas que

${ }^{4}$ Vid., ALONSO CRESPO: Adopción Nacional e Internacional, Panorámica procesal y sustantiva, incluida la intervención de los padres biológicos. Formularios. Anexos, La Ley, Madrid, 2004, p. 67.

${ }^{5}$ A cuarenta y cinco años máximos de diferencia eleva el artículo 36.2.e) del Decreto 58/2002, de 30 de mayo, de la CA Cantabria de procedimientos relativos a la protección de menores y a la adopción y regula el Registro de protección de la infancia y adolescencia, tomando en consideración en el caso de parejas al miembro más joven.

${ }^{6}$ Exigen esta diferencia de cuarenta años: Ley 9/2003, 23 diciembre, de medidas tributarias y administrativas de Galicia (artículo 23), salvo en los casos de adopción de grupos de hermanos o menores con especiales dificultades, casos en que la diferencia de edad podrá ser superior; Decreto 5/2003, de 14 de enero, del procedimiento de valoración de las solicitudes de adopción y acogimiento familiar y de selección de adoptantes y acogedores, de la CA de Extremadura (artículo 30.2.b) salvo en los casos de adopción de grupos de hermanos o menores con especiales dificultades; Ley 6/1995, de 28 de marzo, de garantías de los derechos de la infancia y la adolescencia en la Comunidad de Madrid (artículo 59.1), en el caso de adopción por parejas se considerará la edad media de ambos; Decreto 37/2005, de 12 de mayo, por el que se regulan los procedimientos administrativos y otras actuaciones complementarias en relación con la adopción de menores de Castilla-León (artículo 28.2.a), salvo en los casos de adopción de grupos de hermanos o menores con especiales dificultades y en el caso de adopciones suscritas por dos personas se considerará la media aritmética de las edades correspondientes a cada una de ellas, determinándose la edad de los menores que pueden ser adoptados. No obstante, esta normativa puede variar, por lo que es conveniente tener constancia siempre de las vigentes. 
desean formalizar una adopción para tener la consideración de idóneas, es necesario tener presente la normativa autonómica que se ocupa de esta materia ya que la misma lo suele especificar. De esta forma a los preceptos previstos por el texto legal deberán sumarse los correlativos a las diferentes normativas autonómicas, dictadas en asunción de la asistencia social y que se encuentran amparadas tanto por la CE en su artículo 148. 1. 20, como por los Estatutos de Autonomía respectivos, e incluso las dictadas en asunción de la legislación civil dentro del marco delimitado por la $\mathrm{CE}$ en su artículo 149. 1. 87.

Por otra parte, en los supuestos de solicitud conjunta por ambos cónyuges o por pareja unida de forma estable con relación de afectividad análoga a la conyugal, será suficiente con que uno de ellos haya alcanzado los veinticinco años de edad cumplidos ${ }^{8}$. Mientras que en los casos de solicitud de adopción del hijo del cónyuge o de la pareja sentimental -al no tratarse de una adopción conjunta, puesto que el menor ya tiene un padre o una madre ${ }^{9}$-, sí resulta necesario que el adoptante tenga cumplida la edad mínima establecida en veinticinco años, con independencia de que su cónyuge o compañero/a sentimental haya alcanzado dicha edad.

Del análisis de la redacción del precepto conviene precisar que establece una diferencia mínima de edad entre adoptando y adoptante -cifrada en catorce años-, con la pretensión de que la filiación adoptiva se asimile en la medida en que sea posible a la filiación natural o biológica. Por lo que el adoptante deberá tener por lo menos catorce años más que el adoptado.

${ }^{7}$ En relación sobre el reparto de competencias entre el Estado y las CCAA en materia de protección de menores, vid., entre otros, ALONSO CRESPO, op. cit., p. 98; QUESADA GONZÁLEZ: La Adopción. Un estudio de sentencias, autos y resoluciones, Atelier, Barcelona, 2004, p. 16; GARrido CHAMORRo: Instituciones de Derecho Privado, IV, Familia, Vol. 2, coordinado por Juan Francisco Delgado de Miguel, Civitas, Madrid, 2002, pp. 683 y ss.; VARGAS CABRERA: «El acogimiento de menores. Concepto. Clases. Acogimiento judicial y administrativo. Cesación del acogimiento. La guarda de hecho», en Curso sobre Instituciones de protección de menores, Cuerpo de Secretarios Judiciales III, CEJAJ, Madrid, 1998, p. 106; PÉREz Álvarez: La nueva adopción, Civitas, Madrid, 1989, pp. 62 y ss.

${ }^{8} \mathrm{Vid}$., en este sentido, Díaz-AMBrona Bardají y Hernández Gil, sostiene que «podrá adoptar un menor de quince años casado con la dispensa establecida en el artículo 48 del Código civil, a otro menor recién nacido o con pocos meses de vida (art. 175.1 CC), pues debe existir entre ellos la diferencia de catorce años» (Lecciones de Derecho de Familia, Centro de Estudios Ramón Areces, Madrid, 2007, 2. ${ }^{a}$ ed., p. 384).

${ }_{9}$ Es de la misma opinión, Alonso CRESPO, op. cit., p. 71. 
De modo que en los supuestos de adopciones llevadas a cabo por matrimonios o por parejas estables con relación de afectividad análoga a la conyugal, cada uno de los adoptantes deberán tener por lo menos catorce años más que el adoptando, sin que baste el hecho de que lo tenga uno sólo. Conclusión a la que se llega debido a la expresión «En todo caso» utilizada por el artículo 175.1 del texto legal.

En relación a la necesidad de la concurrencia del requisito de la diferencia mínima de edad entre el adoptando y el adoptante, la Sentencia de la Audiencia Provincial de Barcelona de 14 de febrero del 2001, considera nula la adopción de dos hermanos, debido a que la adoptante solamente es cinco años mayor que el adoptando y ocho que la adoptanda, lo que origina que se deje sin efecto el cambio de apellidos de los actores y pasen a ostentar el que tenían de origen.

En suma, este supuesto es un claro caso de nulidad por la inexistencia de uno de los requisitos sustantivos y esenciales exigidos tanto en el Código civil como en el reciente Código civil de Cataluña ${ }^{10}$. Preceptos que requieren, necesariamente, que el adoptante sea mayor de veinticinco años y tenga como mínimo catorce años más que la persona adoptada ${ }^{11}$. Requisito último que no se da entre los actores con relación a la demandada, tal y como queda acreditado en las certificaciones de nacimiento de éstos y en la anotación marginal de la adopción.

Por último, y siguiendo a Díaz-AmBrona, conviene precisar que aunque el Código civil emplee únicamente el masculino para referirse a la persona que puede adoptar al utilizar el término «el adoptante», esto no supone la exclusión de la mujer, ya que cualquier persona, sea hombre o mujer, que sea mayor de veinticinco años puede ser adoptante $^{12}$.

${ }^{10}$ Por Ley 25/2010, de 29 de julio, ha sido aprobado el libro segundo del Código civil de Cataluña, relativo a la persona y la familia, que entrará en vigor el próximo 1 de enero de 2011, y que deroga la Ley 9/1998, de 15 julio, del Código de familia, la Ley 10/1998, de 15 de julio, de uniones estables de pareja y la Ley 19/1998, de 28 de diciembre, sobre situaciones convivenciales de ayuda mutua.

${ }^{11}$ Cfr. Artículo 175.1 del Código civil y Artículo 235-30.1.b) de la Ley 25/2010, de 29 de Julio, del libro segundo del Código civil de Cataluña, relativo a la persona y la familia.

12 Díaz-Ambrona Bardají y Hernández Gil: Lecciones de Derecho de Familia, Centro de Estudios Ramón Areces, Madrid, 1999, p. 373; Díaz-AMBrona BARDaJí y HERNÁNDEZ GIL: Lecciones de Derecho..., 2007, op. cit., p. 383. 


\section{La capacidad del adoptante: el caso de los adoptantes incapacitados judicialmente}

En el Código civil no se exige que el adoptante esté en "pleno ejercicio de todos sus derechos civiles», ya que con la Ley 21/1987, de 11 de noviembre, de modificación del Código Civil y la Ley de Enjuiciamiento Civil en materia de adopción y otras formas de protección de menores, se suprimió tal exigencia. Esto origina la posibilidad de que puedan ser adoptantes, tanto los incapaces ${ }^{13}$, como los menores emancipados, siempre y cuando reúnan los requisitos establecidos en el artículo 175.1 del Código civil ${ }^{14}$.

En relación al primer supuesto, conviene puntualizar que el artículo 200 del texto legal dispone que «son causas de incapacitación las enfermedades o deficiencias persistentes de carácter físico o psíquico, que impidan a la persona gobernarse por sí misma». De modo que al adoptante lo que se le exigirá en el momento de la prestación del consentimiento a la adopción será la capacidad necesaria para otorgar válidamente ese consentimiento. Consentimiento que, indudablemente, no podrán prestarlo las personas que hayan sido incapacitadas por sentencia judicial conforme a lo previsto en dicho precepto.

En este sentido, PeÑa Bernaldo de Quirós, dice que «en los casos de incapacitación psíquica habrá de estarse a los términos de la sentencia, pudiendo únicamente adoptar el incapacitado cuando pueda emitir el consentimiento por sí mismo y con plena consciencia, lo cual solamente podrá tener lugar en el caso de incapacitados por anomalías psíquicas durante un intervalo lúcido» ${ }^{15}$.

En cuanto al segundo supuesto, la nueva redacción del artículo 175.1 suprime la misma exigencia que en el caso anterior, por lo que tampoco existe ningún impedimento para que puedan adoptar los menores emancipados, pero en este caso sí será necesaria la concurrencia de dos requisitos: De una parte, que se encuentre casado o forme una unión de hecho -siempre y cuando el cónyuge o pareja

${ }^{13}$ En estos casos, se puede entender que lo lógico es que la solicitud de adopción no prospere, debido a la apreciación de su falta de idoneidad para ser adoptantes al no poder gobernarse por sí solos.

${ }^{14}$ En el mismo sentido, Quesada GonZález, op. cit., p. 19. Por su parte, Lasarte ÁlVAREZ, entiende que «no pueden adoptar los incapacitados (salvo que otra cosa se deduzca de la sentencia de incapacitación) y, por principio, los menores de edad, estén o no incapacitados o emancipados, pues las condiciones de edad expresamente establecidas excluyen de raíz tal posibilidad» (Vid., op. cit., p. 332).

${ }^{15}$ Peña Bernaldo de Quirós: Derecho de Familia, Servicio de Publicaciones de la Universidad Complutense, Madrid, 1989, p. 470. 
sentimental tenga veinticinco años cumplidos- $y$, de otra, que tenga catorce años más que el adoptando ${ }^{16}$.

A este respecto, conviene precisar que con la reciente reforma llevada a cabo por el Código civil de Cataluña ${ }^{17}$, se elimina dicha exigencia, equiparándose en este aspecto al Código civil. No obstante, conviene precisar que aunque nuestro Código civil a diferencia del Código civil de Cataluña no lo diga, para ser adoptante se requiere tener plena capacidad de obrar. De modo que ahora este texto legal también permite la posibilidad de que puedan ser adoptantes, tanto los incapaces, como los menores emancipados, siempre y cuando reúnan los requisitos previstos por el precepto ${ }^{18}$ contenido en dicho texto.

Por otra parte, a diferencia de la ya derogada Ley 10/1998, de 15 de julio, de uniones estables de pareja, el vigente Código civil de Cataluña, en la regulación de la convivencia estable en pareja contenida en su libro segundo: De una parte, excluye de forma expresa la posibilidad de que los menores no emancipados puedan constituir pareja estable ${ }^{19}$, y de otra, suprime las diferencias por razón de la orientación sexual de los miembros de la pareja. De modo que se permite la constitución de pareja estable a los menores emancipados -siendo tenidos como mayores de edad a los efectos de la constitución de parejas estables, capacidad que no le era reconocida con la anterior legislación- y, se elimina cualquier vestigio discriminatorio por razón de sexo, por lo que ya no existe distinción entre pareja estable homosexual y heterosexual.

\section{Adopción Conjunta}

Del Código civil se desprende que podrán ser adoptantes una perso-

${ }^{16}$ Vid., QUESADA GonZÁLEZ, op. cit., p. 20.

${ }^{17}$ Ley 25/2010, de 29 de Julio, del Libro Segundo del Código civil de Cataluña, relativo a la Persona y la Familia, deroga la anterior Ley 9/1998, de 15 de julio, del Código de Familia, de la Generalitat de Cataluña.

${ }_{18}$ Dice el «Artículo 235-30. Requisitos personales para adoptar. -1. Para poder adoptar deben cumplirse los siguientes requisitos: a) Tener plena capacidad de obrar. b) Ser mayor de veinticinco años, salvo que se trate de la adopción del hijo del cónyuge o de la pareja estable o de parientes huérfanos, y tener como mínimo catorce años más que la persona adoptada», redactado por Ley 25/2010, de 29 de Julio, del libro segundo del Código civil de Cataluña, relativo a la persona y la familia.

${ }^{19}$ Según el «Artículo 234-2. Requisitos personales. No pueden constituir una pareja estable las siguientes personas: a) Los menores de edad no emancipados», redactado por Ley 25/2010, de 29 de Julio, del libro segundo del Código civil de Cataluña, relativo a la persona y la familia. 
na sola -hombre o mujer ${ }^{20}$-, conjuntamente los cónyuges ${ }^{21}$, o el hombre y la mujer que integren una pareja unida de forma permanente por relación de afectividad análoga a la conyugal ${ }^{22}$. De modo que podrá ser adoptante una persona sola o dos personas y la relación entre éstas podrá ser consecuencia del matrimonio o de una unión de hecho.

Conforme a la Disposición Adicional Tercera de la Ley 21/1987, de 11 de noviembre, de modificación del Código Civil y la Ley de Enjuiciamiento Civil en materia de adopción y otras formas de protección de menores, se observa que con el término de "parejas unidas de forma permanente [...]», se hacía referencia a las parejas de unión de hecho estable, pero siempre de distinto sexo. Salvedad superada por la Ley 13/2005, de 1 de julio, por la que se modifica el Código Civil en materia de derecho a contraer matrimonio, ya que en su Disposición Adicional Primera se establece que: «Las disposiciones legales y reglamentarias que contengan alguna referencia al matrimonio se entenderán aplicables con independencia del sexo de sus integrantes».

En este sentido, conviene precisar que la admisión legal de la adopción conjunta por una pareja estable integrada por personas de distinto sexo no planteaba problema alguno, mientras que tanto la legislación estatal como la mayoría de las legislaciones autonómicas no permitían la adopción llevada a cabo por parejas estables integradas por personas de igual sexo, es decir, parejas homosexuales.

En la actualidad, la adopción por parejas de hecho estable ${ }^{23}$ del mismo sexo es permitida, entre otras: por el artículo 8 de la Ley

${ }^{20}$ Cuando la adopción es llevada a cabo por una persona sola, ya sea esta hombre o mujer, soltero, viudo, divorciado, separado y con o sin hijos, se hace referencia a la adopción unipersonal, la cual no tendrá lugar cuando se den determinados supuestos especiales en relación con el adoptando, es decir, que fuera pariente del adoptando o que éste presente algún tipo de problemas para poder ser adoptado.

${ }^{21}$ Cuando un hombre y una mujer adoptan a una misma persona a la vez, cabe decir que lo están haciendo de forma conjunta y/o simultáneamente.

22 Disposición Adicional Tercera de la Ley 21/1987, de 11 de noviembre, de modificación de determinados artículos del Código civil y de la Ley de Enjuiciamiento Civil en materia de adopción.

${ }^{23} \mathrm{Vid}$., en este sentido, PouS DE LA FLOR, -quien- ha realizado un examen exhaustivo sobre las CCAA que han sido las pioneras en dictar leyes en materia de parejas estables o de hecho, y que han tomando en consideración la posibilidad de que sean adoptantes parejas integradas por personas del mismo sexo. Asimismo, también se detiene en el estudio de los recursos de inconstitucionalidad a los que algunas de estas Leyes fueron sometidas («La adopción por las parejas de hecho», en Perspectivas del derecho de familia en el siglo XXI: XIII Congreso Internacional de Derecho de Familia. Coordinado por Carlos LaSarte Álvarez, Araceli Donado Vara, María Fernanda Moretón SANZ y Fátima Yáñez VIVERo, Sevilla, 2004, pp. 3943 y ss.). 
Foral Vasca 2/2003, de 7 de mayo, reguladora de las parejas de hecho $^{24}$, el artículo 8 de la Ley Foral Navarra 6/2000, de 3 de Julio, para la igualdad jurídica de las parejas estables ${ }^{25}$, el artículo 11.1 de la Ley 1/2005, de 16 de mayo, de parejas de hecho de la CA de Cantabria $^{26}$, el artículo 10 de la Ley $2 / 2004$, de 3 de mayo, relativa a parejas estables no casadas de Aragón ${ }^{27}$ y el artículo 1 de la Ley 3/2005, de 8 de abril, de modificación de la Ley 9/1998, del Código de Familia, de la Ley 10/1998, de uniones estables de pareja y de la Ley 40/1991, del Código de Sucesiones por causa de muerte en el Derecho Civil de Cataluña en materia de Adopción y de Tutela ${ }^{28}$.

De acuerdo con la importancia que tiene hoy por hoy la adopción por parejas estables de hecho, conviene recordar que el artículo 8 de la Ley $2 / 2003$, de 7 de mayo, reguladora de las parejas de hecho del País Vasco, que permite la adopción conjunta por personas de igual sexo, estaba pendiente del recurso de inconstitucionalidad (núm. 5174/2003), promovido por la Presidencia del Gobierno, en el cual se invocó el artículo 161.2 de la Constitución Española ${ }^{29}$-en adelante $\mathrm{CE}-$, lo que dio lugar a la suspensión de la vigencia y aplicación del precepto impugnado. En fecha relativamente reciente, por Auto del Tribunal Constitucional de 14 de diciembre de 2004, se ha acordado tener por desistido al Abogado del Estado en dicho recurso de inconstitucionalidad y declarar extinguido el proceso.

En este sentido, el Auto del Juzgado de $1^{a}$ Instancia Núm. 2 de

24 «Artículo 8.-1. Los miembros de parejas formadas por dos personas del mismo sexo podrán adoptar de forma conjunta, con iguales derechos y deberes que las parejas formadas por dos personas de distinto sexo y las parejas unidas por matrimonio. 2. La hija o hijo adoptivo o biológico de una de las partes de la pareja tendrá derecho a ser adoptado por la otra parte».

25 «Artículo 8.-1. Los miembros de la pareja estable podrán adoptar de forma conjunta con iguales derechos y deberes que las parejas unidas por matrimonio. 2 . Se adecuarán las disposiciones normativas forales sobre adopciones y acogimiento para contemplar el modelo de familia formado por parejas estables».

26 "Artículo 11.-1. La pareja de hecho podrá acoger y adoptar con iguales derechos y deberes que las parejas unidas por matrimonio de acuerdo con la legislación aplicable».

27 «Artículo 10. Las parejas estables no casadas podrán adoptar conjuntamente».

28 «Articulo 1. Sólo se admite la adopción por más de una persona en el caso de los cónyuges o de las parejas que conviven de forma estable. En tales casos, es suficiente que una de las personas que adopta haya cumplido los veinticinco años».

${ }_{29}^{29}$ "Artículo 161. -2. El Gobierno podrá impugnar ante el Tribunal Constitucional las disposiciones y resoluciones adoptadas por los órganos de las Comunidades Autónomas. La impugnación producirá la suspensión de la disposición o resolución recurrida, pero el Tribunal, en su caso, deberá ratificarla o levantarla en un plazo no superior a cinco meses». 
Gernika-Lumo Vizcaya de 21 de febrero de 2005, procede a acceder a la adopción de los hijos previamente adoptados por la pareja de hecho homosexual de la adoptante.

Por lo que, a tenor de dicho auto, conviene tener presente que la interpretación normativa deberá ajustarse a la realidad social del tiempo de su vigencia, entendiendo que una persona unida por una relación de afectividad permanente y estable a otra, de hecho, es constitucionalmente equiparado al matrimonio en todos los ámbitos de nuestro ordenamiento jurídico, siendo en el ámbito civil, penal, laboral y administrativo, la equiparación de las parejas de hecho a los matrimonios plena.

Por otra parte, en el supuesto, hay que hacer constar que la solicitante convivía con su pareja y se encontraban ambas inscritas como unión civil en el Registro del Ayuntamiento de su lugar de residencia -así consta en el certificado expedido por el mismo-. Asimismo, los adoptandos habían convivido con la solicitante desde el nacimiento, y ésta había sido nombrada tutora y administradora de los bienes de aquéllos ante Notario, mediante testamento otorgado por la compañera sentimental de la solicitante.

De modo que al caso según dicho auto le será de aplicación la Ley Foral Vasca 2/2003, de 7 de mayo, reguladora de las parejas de hecho, debido a que la Ley aplicable de la pareja sería la más cercana a la figura de unión «more uxorio» definida por el hecho de la convivencia.

\section{Adoptantes en la Ley Foral Navarra 6/2000, de 3 de julio}

En primer lugar, conviene recordar que la Ley 6/2000, de 3 de julio, para la igualdad jurídica de las Parejas Estables, del Parlamento de Navarra, fue la pionera en España, resolviendo un órgano jurisdiccional de forma favorable con base en ella la pretensión de adoptar por una lesbiana respecto de las hijas de la compañera sentimental con la que convivía ${ }^{30}$.

\footnotetext{
${ }^{30}$ Vid., Auto del Juzgado de $1^{\text {a }}$ Instancia Núm. 3 (familia) de Pamplona de 22 de enero de 2004, conforme al cual se dictó una sentencia favorable a una mujer que solicitó la adopción de dos menores, hijas biológicas de su compañera sentimental -ambas niñas fueron concebidas por técnicas de reproducción asistida y desde su nacimiento habían convivido con su madre biológica y con la mujer que hoy es su madre adoptiva-, a la misma le fue de aplicación la Ley Foral 6/2000, de 3 de julio, para la igualdad jurídica de las parejas estables, que acepta la adopción de una pareja estable no casada con independencia de su identidad sexual. El Juzgado con-
} 
El párrafo primero de su artículo 8, dice que: «Los miembros de la pareja estable podrán adoptar de forma conjunta con iguales derechos y deberes que las parejas unidas por matrimonio». Por lo que, esta norma no se refiere en concreto a las parejas del mismo sexo, pero con la expresión «miembros de la pareja estable», todo apunta a que parece incluirlos de forma tácita, debido a que no están excluidos expresamente.

En este sentido, el artículo 2 del mismo texto legal, al objeto de determinar quiénes pueden ostentar la condición de adoptantes según esta normativa, en su apartado primero, considera como pareja estable: «La unión libre y pública, en una relación de afectividad análoga a la conyugal, con independencia de su orientación sexual, de dos personas mayores de edad o menores emancipadas sin vínculo de parentesco por consanguinidad o adopción en línea recta o colateral hasta el segundo grado, siempre que ninguna de ellas esté unida por un vínculo matrimonial o forme pareja estable con otra persona».

Por lo que para que la aplicación de esta norma sea efectiva será necesario que « $[\ldots]$ al menos, uno de los miembros de la pareja tenga la vecindad civil navarra ${ }^{31}$.

Con este precepto se restringe la posibilidad de constituir pareja estable a aquéllas personas que tuvieran entre sí un vínculo de parentesco por consanguinidad o adopción en línea recta o colateral hasta el segundo grado.

De lo dicho, conviene precisar que en el caso de dos hermanos adoptivos -ya sean hijos adoptivos ambos, o uno adoptivo y otro biológico-, éstos podrán contraer matrimonio entre sí, puesto que lo permite el artículo $47.2^{\circ}$ del Código civil que establece la incapacidad matrimonial a «los colaterales por consanguinidad hasta el tercer grado», capacitando de forma implícita a los «colaterales por adop-

sideró que no era la intención del legislador la de excluir los supuestos de adopción sucesiva, consecuencia de una maternidad previa individual, ya que sólo trató la adopción conjunta, realizada simultáneamente. Y además, se apoyó en que la legislación común permite la adopción con independencia de la identidad sexual, así como se sirvió de los informes realizados por el Centro de Planificación Familiar al que la pareja acudió con la intención de acceder a la maternidad mediante técnicas de reproducción asistida, utilizando tanto el informe previo al nacimiento como los llevados con posterioridad donde se reflejó un resultado favorable, ya que ambas partes poseen una estabilidad psicológica, familiar, personal y socioeconómica favorable, de forma que se les reconocía como núcleo familiar adecuado e idóneo para favorecer el desarrollo de las menores.

${ }^{31}$ Cfr. Artículo 2.3 de la Ley 6/2000, de 3 de julio, para la igualdad jurídica de las Parejas Estables, del Parlamento de Navarra. 
ción ${ }^{32}$, pero a los efectos de esta Ley Foral, no podrán constituir pareja estable, al quedar excluidos del concepto antes enunciado.

En síntesis, dos hermanos adoptivos, varón y mujer, no podrán constituir pareja estable y no podrán adoptar conjuntamente ${ }^{33}$, al igual que dos hermanos adoptivos, ya sean ambos varones o mujeres podrán convivir, pero no constituir pareja, por lo que tampoco podrán adoptar ${ }^{34}$.

Por su parte, el párrafo segundo del artículo 2, dispone que: «Se entenderá que la unión es estable cuando los miembros de la pareja hayan convivido maritalmente, como mínimo, un período ininterrumpido de un año, salvo que tuvieran descendencia común, en cuyo caso bastará la mera convivencia, o salvo que hayan expresado su voluntad de constituir una pareja estable en documento público».

Por lo que, la pareja estable qué esté capacitada para llevar a cabo una adopción conjunta -según el artículo 8 de dicha Ley-, se podrá constituir de tres formas diferentes: De una parte, por la convivencia marital durante un periodo mínimo e ininterrumpido de un año; de otra, por la mera convivencia en caso de la existencia de descendencia común, y, finalmente, por la expresión en documento público de la voluntad de constituir una pareja estable.

De modo que los integrantes de una pareja formada por personas del mismo sexo que deseen llevar a cabo una adopción, deberán acreditar ante la entidad pública y ante el Juez mediante todo tipo de pruebas, que su convivencia se ha desarrollado por un tiempo superior a un año, pudiendo de pleno derecho aspirar a una adopción conjunta.

Finalmente, conviene precisar que esta Ley Foral sigue pendiente de un Recurso de inconstitucionalidad (núm. 5297/2000), que fue promo-

${ }^{32}$ Sin embargo, sí que serán incluidos en la incapacidad matrimonial de los parientes consanguíneos en línea recta contenida en el artículo 47.1 del Código civil, redactado por Ley 30/1981, de 7 de julio, por la que se modifica la regulación del matrimonio en el Código Civil y se determina el procedimiento a seguir en las causas de nulidad, separación y divorcio.

${ }^{33}$ De esta forma, se observa que se produce una perdida en las expectativas de adopción conforme a la vecindad civil navarra de los miembros de la pareja, ya que las posibilidades de adopción conjunta que se les reconocería (Disposición Adicional Tercera de la Ley 21/1987, de 11 de noviembre), desaparecen con la Ley Foral Navarra al aplicarse el concepto de pareja estable de la misma, lo cual no afecta al hecho de que estén unidos por parentesco colateral por adopción.

${ }^{34}$ Cfr. Artículo 8 de la Ley 6/2000, de 3 de julio, para la igualdad jurídica de las Parejas Estables, del Parlamento de Navarra. 
vido por ochenta y tres Diputados del Grupo Parlamentario Popular, y admitido a trámite por providencia de 31 de octubre de 2000, pero a diferencia de la Ley Foral Vasca 2/2003, de 7 de mayo, reguladora de las parejas de hecho -a la que se hizo referencia en el epígrafe anterior-, ni se suspendió la vigencia ni la aplicación de la Ley impugnada, de modo que prevalece la presunción de su legitimidad y validez, en tanto no se resuelva el recurso de inconstitucionalidad interpuesto.

\section{Adopción Sucesiva}

Conforme a la nueva redacción del artículo 175.4 del Código civil: «Nadie puede ser adoptado por más de una persona, salvo que la adopción se realice conjunta o sucesivamente por ambos cónyuges. El matrimonio celebrado con posterioridad a la adopción permite al cónyuge la adopción de los hijos de su consorte. En caso de muerte del adoptante, o cuando el adoptante sufra la exclusión prevista en el artículo $179^{35}$, es posible un nueva adopción del adoptado» ${ }^{36}$.

Del tenor literal del precepto se desprende que la «muerte» o «exclusión» del adoptante no comporta la extinción de la adopción, puesto que el artículo permite una nueva adopción. No obstante, como nadie puede estar adoptado por más de una persona -salvo que se realice de forma conjunta o sucesiva por ambos cónyuges-, la nueva adopción extinguirá la precedente, así como la primera adopción extinguía los vínculos del adoptado con su familia anterior.

Asimismo, en aquellos supuestos en los que falleciera o fuera excluido sólo uno de los adoptantes, la segunda adopción sólo sería posible por el cónyuge del otro adoptante, puesto que este último sigue siéndolo y, por tanto, lógico es que se extingan los vínculos adoptivos respecto del anterior y de su familia, pero seguiría vigente para el otro cónyuge, actuando como una adopción sucesiva.

35 «Artículo 179.-1. El Juez, a petición del Ministerio Fiscal, del adoptado o de su representante legal, acordará que el adoptante que hubiere incurrido en causa de privación de la patria potestad, quede excluido de las funciones tuitivas y de los derechos que por Ley le correspondan respecto al adoptado o sus descendientes, o en sus herencias.-2. Una vez alcanzada la plena capacidad, la exclusión sólo podrá ser pedida por el adoptado, dentro de los dos años siguientes.-3. Dejarán de producir efecto estas restricciones por determinación del propio hijo una vez alcanzada la plena capacidad».

${ }^{36}$ Núm. 4 del artículo 175 redactado por Ley 13/2005, de 1 de julio, por la que se modifica el Código Civil en materia de derecho a contraer matrimonio. 
Por otra parte, conviene recordar que el adoptando, no recuperará nunca los vínculos con la familia anterior, puesto que la adopción produce la extinción de los vínculos jurídicos entre el adoptado y su familia de origen ${ }^{37}$.

Del tenor literal del precepto se observa que con la expresión «familia anterior» no se establece que ésta sea adoptiva o biológica, por lo que, en principio, se puede entender que tendrán cabida ambas.

Otro cuestión a tener en cuenta en el estudio de la figura radica en el hecho de que los padres, ya sean éstos biológicos o adoptivos, una vez son excluidos -lógicamente por no ser capaces de proteger al hijo-, ya no pueden volver a ocupar esta posición, pero conviene precisar que podrán ser acogedores o tutores del adoptado si el adoptante hubiera fallecido ${ }^{38}$ o hubiera sido excluido, y cuando el interés del menor así lo exija.

En definitiva, este precepto hace referencia tanto a la «adopción única» como a la «adopción conjunta o sucesiva por ambos cónyuges». No obstante, conviene matizar que en la adopción sucesiva el segundo en adoptar será el adoptante, ya que el adoptado fue adoptado inicialmente por otra persona, de modo que ya tiene un padre o madre adoptiva y, en consecuencia, ya se encuentra adoptado ${ }^{39}$, por lo que ahora lo que va a completar es su filiación adoptiva. Por tanto, se admite la adopción por una persona (adopción única) cuando la adopción anterior, ya sea materna, paterna o ambas, ya no exista, bien sea por causa de muerte o por la exclusión del adoptante. Supuestos en los que la adopción posterior extinguirá a la anterior, salvo que el siguiente en adoptar sea el cónyuge o la pareja estable del adoptante fallecido o excluido ${ }^{40}$.

${ }^{37}$ Cfr. Artículo 178.1 del Código civil.

38 «Artículo 222. Estarán sujetos a tutela:-1. Los menores no emancipados que no estén bajo la patria potestad».

${ }^{39}$ Hualde Sánchez sostiene que el artículo 175 debería decir que no se puede estar adoptado a la vez por más personas que los dos cónyuges, aunque si bien termina diciendo que pueden ser pareja estable, ya que las posibilidades jurídicas son múltiples, por ejemplo, la primera adopción pudo romper los vínculos con las dos familias iniciales tanto la paterna como la materna, aunque también pudo dejar vigente alguna de ellas. Por tanto, si el adoptado conservara la filiación biológica respecto del padre o madre, para ser adoptado por el cónyuge de su padre o madre adoptivo, el biológico deberá asentir tal adopción, salvo que hubiera fallecido o hubiera sido privado de su derecho de veto a la adopción, (Vid., Comentarios a las reformas del Código Civil. Coordinado por Rodrigo BERCovitz y Rodriguez-Cano, Tecnos, Madrid, 1993, pp. 149 y 150).

${ }^{40} \mathrm{Vid}$., es de la misma opinión, ALONSO CRESPO, op. cit., p. 71. 


\section{Adopción «Post Mortem»}

El párrafo tercero del artículo 176 del Código civil dispone que: «En los tres primeros supuestos del apartado anterior podrá constituirse la adopción, aunque el adoptante hubiere fallecido, si éste hubiere prestado ya ante el Juez su consentimiento. Los efectos de la resolución judicial en este caso se retrotraen a la fecha de la prestación de tal consentimiento».

Los supuestos a los que se refiere el precepto, y que no requieren de propuesta previa, se encuentran contenidos en su párrafo segundo. Estos supuestos se presentan en los siguientes términos:

« $1^{\circ}$. Ser huérfano y pariente del adoptante en tercer grado por consanguinidad o afinidad. $2^{\circ}$. Ser hijo del consorte del adoptante. $3^{\circ}$. Llevar más de un año acogido legalmente bajo la medida de un acogimiento preadoptivo o haber estado bajo su tutela por el mismo tiempo».

Tras el análisis del texto del precepto, la adopción «post mortem» se configura como aquélla que se constituye y es eficaz tras el fallecimiento del adoptante o adoptantes, puesto que se puede constituir aunque los dos adoptantes hubieran fallecido o sólo uno de ellos, siendo en este último caso póstuma respecto de éste.

De modo que podrá ser adoptante una persona que hubiera fallecido -siempre y cuando antes de fallecer, hubiese prestado ante el Juez su consentimiento-, no siendo necesaria la propuesta previa de la entidad pública competente por concurrir en el adoptado determinadas circunstancias ${ }^{41}$.

De lo anterior se sigue que el adoptante deberá haber prestado su consentimiento, es decir, manifestado su voluntad de serlo y haberlo hecho ante el juez, puesto que no sirve el consentimiento otorgado ante persona distinta del juez, ya que el contacto directo entre ambos es especialmente valorado, al igual que ocurre aunque la adopción no sea póstuma ${ }^{42}$.

En este sentido, el Código civil de Cataluña, es más flexible ya que permite el consentimiento a la adopción dado ante la autoridad judicial o bien en testamento, codicilo o escritura pública ${ }^{43}$. Por otra

${ }^{41}$ Cfr. Artículo 176.2 del Código civil.

42 «Artículo 177.-1. Habrán de consentir la adopción, en presencia del Juez, el adoptante o adoptantes y el adoptando menor de doce años».

${ }^{43}$ Cfr. Artículo 235-32.3 de la Ley 25/2010, de 29 de Julio, del libro segundo del Código civil de Cataluña, relativo a la persona y la familia. 
parte, el precepto prevé que únicamente será posible la constitución de la adopción en aquellos supuestos en los que el adoptando sea hijo del cónyuge o de la persona con que convive en relación de pareja estable, o huérfano y pariente del adoptante hasta el cuarto grado de consanguinidad o afinidad, o que estuviera sometido a tutela o, en situación de acogimiento preadoptivo o de desamparo.

En relación a los efectos que produce, se puede decir que en principio son los mismos que los que originaría cualquier otro tipo de adopción. No obstante, la diferencia radica en que los efectos de la resolución judicial constitutiva de la adopción se retrotraen a la fecha de la prestación del consentimiento del adoptante, siendo incuestionable que esto tiene su importancia a efectos sucesorios, puesto que permite proteger los derechos del adoptando con relación a la herencia del adoptante y a otras herencias a las que podría resultar llamado o excluido en el caso de la constitución de ésta, ya que en caso contrario no tendría sentido, debido a que éste ya habría fallecido y el adoptando no podría heredarle, puesto que el fallecimiento del adoptante sería el que establecería la normativa sobre su sucesión ${ }^{44}$.

LETE DEL Río, dice que «no puede afirmarse que el consentimiento del adoptante por sí sólo confiera derecho a constituir la adopción, ya que ésta podrá o no constituirse, encontrándose supeditada a la valoración de la autoridad judicial y debiendo tener en cuenta el interés del adoptando» ${ }^{45}$.

En síntesis, la adopción "post mortem» encuentra su justificación en el interés del adoptado, debiendo ser el Juez quien valore la conveniencia de la adopción, teniendo en cuenta, entre otros extremos, la inserción del menor en la familia del adoptante, los beneficios econó$\operatorname{micos}[\ldots]$.

Para finalizar y en relación a la necesidad de la prestación del consentimiento ante el Juez aunque el adoptante hubiera fallecido, conviene citar el Auto de la Audiencia Provincial de Badajoz de 30 de junio de 2004, en el que se procede al archivo de la causa, ya que se produce el fallecimiento del adoptante durante la tramitación de la causa y antes de haber prestado su consentimiento ante la autoridad judicial, hecho que hace inviable la aprobación de la adopción de la menor ${ }^{46}$.

${ }^{44}$ Vid., QueSADa GonZÁlez, op. cit., p. 19.

${ }^{45}$ LETE DEL Río: «Personas que pueden adoptar y ser adoptadas», $A C$, Núm. 5, febrero, 1991, pp. 75 y ss.

${ }^{46}$ Cfr. Artículo 176.3 del Código civil. 


\section{SUJETOS SUSCEPTIBLES DE SER ADOPTADOS}

\section{Menores no emancipados}

Dice el artículo 175.2 del Código civil, que: «Únicamente podrán ser adoptados los menores no emancipados. Por excepción, será posible la adopción de un mayor de edad o de un menor emancipado cuando, inmediatamente antes de la emancipación, hubiere existido una situación no interrumpida de acogimiento o convivencia, iniciada antes de que el adoptando hubiere cumplido los catorce años».

En primer término, del tenor literal del precepto se desprende que podrán ser adoptandos los menores no emancipados, debido a que la adopción, ante todo, es una institución de protección de menores, entendiendo por menores a aquéllos que no han adquirido la mayoría de edad. Mayoría de edad tiene lugar al cumplir los dieciocho años ${ }^{47}$.

De modo que dentro de esta acepción se pueden diferenciar claramente tres tipos de menores en función de la edad que los mismos ostenten. Esta clasificación, es la siguiente:

Los menores hasta catorce años, a los que el Código civil no permite la emancipación antes de dicha edad, aunque existan importantes razones para ello.

Los menores de catorce a dieciséis años, que no se encuentren emancipados.

Los menores de dieciséis a dieciocho años, siempre y cuando no hayan sido emancipados por razón de matrimonio o por concesión de los que ejerzan la patria potestad o por el Juez.

\section{2. ¿Puede ser adoptado el «Nasciturus»?}

Conforme al Código civil, sí se podrán adoptar los recién nacidos, pero no se prevé la adopción de los «nasciturus». Adopción que se considera excluida de acuerdo con lo establecido por el último párrafo del artículo $177.2 .2^{\circ}$ : «El asentimiento de la madre no podrá prestarse hasta que hayan transcurrido treinta días desde el parto». Párrafo que supone la imposibilidad de constituir la adopción antes de que nazca el concebido ${ }^{48}$.

\footnotetext{
${ }^{47}$ Cfr. Artículo 315 del Código civil.

${ }^{48} \mathrm{Vid}$., en este sentido, Alonso CRespo, op. cit., p. 85; Quesada GonZÁlez, op. cit., p. 20 y, vid., LASARTE Álvarez, op. cit., p. 332.
} 
REFLEXIONES SOBRE LOS REQUISITOS Y LAS PROHIBICIONES...

Téngase presente que las consecuencias inmediatas de este precepto son: instaurar un plazo de reflexión a favor de la madre biológica, con la intención de que pondere la entrega o no del menor en adopción; prohibir la constitución de la adopción durante dicho plazo y considerar nula la constitución llevada a cabo durante el mismo $\mathrm{y}$, por tanto, nulo de pleno derecho el asentimiento, y, finalmente, esclarecer la imposibilidad de adoptar el «nasciturus», debido a que esta figura no es adoptable.

En síntesis, este plazo de reflexión a favor de la madre biológica se justifica en los posibles cambios físicos y psíquicos que podría comportarle el parto. Cambios que exigen un tiempo para que la madre se reponga y asuma las nuevas circunstancias a las que se enfrenta ${ }^{49}$. Por lo que antes de este plazo la madre no estará en condiciones para determinar las consecuencias que podría reportarle la entrega del menor en adopción, ni tampoco lo estará con anterioridad al parto, ya que podría sufrir presiones de otra índole llevándola a tomar decisiones precipitadas ${ }^{50}$.

De lo dicho dos son los aspectos a tener presente: la ilegalidad de la constitución de la adopción, aun cuando se cuente con la conformidad de la madre y, el hecho de que el asentimiento prestado con anterioridad a los treinta días posteriores al parto estará viciado.

En este sentido, en la Sentencia del Tribunal Supremo de la Sala Primera de lo Civil de 21 de septiembre de 1999, se hace referencia al asentimiento de la madre biológica y a la ineficacia del mismo al ser pactado con anterioridad al periodo establecido en el artículo 177.2.2 ${ }^{\circ}$ del Código civil, lo que comporta la nulidad del documento sobre la autorización de la adopción suscrita con anterioridad a la fecha del parto.

Supuesto, en el que la madre biológica, previamente al alumbramiento, suscribió un documento mediante el que, encontrándose embarazada en el octavo mes de gestación y ponderando sus circunstancias personales, emocionales, familiares y económicas, estimaba que no podría hacerse cargo de su futuro hijo, renunciando al mismo de forma

${ }^{49} \mathrm{Vid}$., en la misma línea, GutiérRez SANTIAGO, entiende que este plazo se le impone a la madre para que reflexione, (Constitución de la adopción: Declaraciones relevantes, Cuadernos de Aranzadi Civil 7, Aranzadi editorial, Navarra, 2000, p. 131).

${ }^{50} \mathrm{Vid}$., en este sentido, VARGAS CABRERA: «Régimen jurídico-sustantivo la adopción y funciones del Ministerio fiscal en la protección de Menores a la luz de la Ley Orgánica 1/96», en Protección Jurídica del Menor, Granada, 1997, p. 94; GuTIÉRREZ SANTIAGO, op. cit., p. 131. 
anticipada, una vez hubiese éste nacido, a favor de la entidad pública a los efectos de adopción, acogimiento [...], y anticipando su asentimiento a la adopción, que adquiriría plena validez transcurridos treinta días desde la fecha del nacimiento del menor.

A tenor de dicha sentencia, cabe decir que la renuncia anticipada llevada a cabo por la actora no es válida, ya que colisiona con lo establecido en el artículo 177.2 respecto de los consentimientos exigibles para la eficacia de la adopción, en el que se determina que el consentimiento de la madre no podrá prestarse hasta transcurridos treinta días desde el parto y, por tanto, no existe viabilidad alguna de que el asentimiento a la adopción pueda ser prestado con anterioridad al mismo y tampoco en el periodo de treinta días computados desde el parto, ya que deberá manifestarse transcurrido ese tiempo, y nunca con anterioridad al momento del parto.

Por lo que el asentimiento de la actora resultará nulo de pleno derecho ${ }^{51}$, debido a que contradice una norma de carácter imperativo establecida en el párrafo cuarto del artículo 177.2.2 ${ }^{\circ}$ del texto legal.

Esta cautela legal que tiene por finalidad garantizar la concurrencia plena de las facultades esenciales de libertad y conciencia en la madre biológica, persigue calibrar de forma detenida la renuncia del ejercicio de la maternidad con la cesión en adopción del menor. Por otra parte, se establece un periodo post-parto de treinta días para la recuperación de la madre tanto física como psíquicamente, por lo que la situación personal, emocional [...] en la que se encontraba la actora en el momento en que suscribió el documento de cesión, no era el más idóneo para su asentimiento, puesto que no había transcurrido dicho periodo.

En definitiva, conviene puntualizar que esta Sentencia del Tribunal Supremo refrenda el texto del artículo $177.2 .2^{\circ}$, lo que podría comportar un desplazamiento del contenido del artículo 29 del Código civil: « [...] el concebido se tiene por nacido para todos los efectos que le sean favorables $[\ldots]$ », como podría ser la adopción o el acogimiento en determinadas situaciones.

\section{Los mayores de edad y los menores emancipados como adoptandos: excepcionalidad de esta posibilidad}

La Ley 21/1987, de 11 de noviembre, de modificación del Código Civil y la Ley de Enjuiciamiento Civil en materia de adopción y otras

\footnotetext{
${ }^{51}$ Cfr. Artículo 6.3 del Código civil.
} 
formas de protección de menores, establece que los mayores de edad o menores emancipados no pueden ser objeto de adopción, puesto que ya no necesitan medidas de protección de esta índole, aunque permite la adopción de los mismos de forma excepcional, en los siguientes términos:

« [...] Por excepción, será posible la adopción de un mayor de edad o de un menor emancipado cuando, inmediatamente antes de la emancipación, hubiere existido una situación no interrumpida de acogimiento o convivencia, iniciada antes de que el adoptando hubiere cumplido los catorce años ${ }^{52}$.

Dos son las expresiones que presenta este precepto: De una parte, «mayor edad»y, de otra, «menor emancipado». Por «mayor edad» se entiende que comprende tanto la mayoría de edad obtenida al cumplir la «edad de dieciocho años», como, de acuerdo con lo que establece el artículo 321 del Código civil: «El beneficio de la mayor edad al sujeto a tutela mayor de dieciséis años, otorgada por el Juez, previo informe del Ministerio Fiscal». Mientras que por «menor emancipado» comprende la emancipación que se consigue por «matrimonio del menor», por "concesión de los que ostentan la patria potestad»y la conseguida por "concesión judicial», siendo necesario que en las dos últimas modalidades el menor tenga dieciséis años cumplidos.

Por su parte, el Código civil de Cataluña, en su artículo 235-33 establece que se permite la adopción de: «[...] una persona mayor de edad o una persona emancipada si ha convivido ininterrumpidamente con el adoptante $[\ldots]{ }_{1}{ }^{53}$.

La mayoría de la doctrina reciente ${ }^{54}$ que estudia la adopción de los mayores de edad lleva a cabo una interpretación restrictiva sobre su

${ }^{52}$ Artículo 175.2 del Código civil.

53 «Artículo 235-33. Adopción de personas mayores de edad. Sólo puede ser adoptada una persona mayor de edad o una persona emancipada si ha convivido ininterrumpidamente con el adoptante antes de haber cumplido catorce años o si ha estado en situación de acogimiento preadoptivo, al menos durante los seis meses inmediatamente anteriores al cumplimiento de la mayoría de edad o a la emancipación, y ha seguido conviviendo con él sin interrupción», redactado por Ley 25/2010, de 29 de Julio, del libro segundo del Código civil de Cataluña, relativo a la persona y la familia.

${ }^{54}$ La mayoría de la doctrina pretende que se califique esta convivencia o acogimiento, ya que se requiere como alternativa a la convivencia con los padres biológicos que haya existido, y que la adopción tenga el mismo objetivo que habría tenido si se hubiera llevado a cabo durante la minoría de edad del adoptando (que se tenga en cuenta el interés o beneficio del adoptando) y que por alguna causa no hubiera podido constituirse en aquel momento, considerando que fuera de estos casos 
admisión, y la justifican únicamente cuando tiene el sentido tuitivo de la adopción de menores, y cuando no pudo llevarse a cabo durante la minoría de edad del adoptando.

La jurisprudencia ${ }^{55}$, se centra en comprobar el requisito de la convivencia, iniciada antes de que el adoptando hubiera cumplido los catorce años. Así como los tribunales también tienen en cuenta la integración plena del adoptando en la familia adoptiva.

De lo dicho conviene precisar que será necesario que el adoptando haya convivido con el adoptante de forma ininterrumpida desde antes de haber cumplido los catorce años hasta su emancipación comprendiendo también la mayoría de edad, adquirida a los dieciocho años, ya que a partir de este momento la persona es libre de establecer vida independientemente.

En relación a los supuestos de menores emancipados, cabe distinguir dos situaciones. De una parte, aquélla en la que la emancipa-

no ha lugar a la misma, ya que puede dar lugar a un fraude de Ley. Vid., en este sentido, García CANTERo: La adopción de mayores de edad, $A C$, Núm. 41, 1998, pp. 993 y ss.; CORTADA CORTINA: La adopción: presupuesto y requisitos legales, en Protección de menores, acogimiento y adopción, Santiago ESPIAU ESPIAU y Antoni VAQuer Aloy (Eds.), Marcial Pons, Barcelona, 1999, p. 159.

La acreditación en el caso del acogimiento es fácil, puesto que se realiza por medio del expediente de acogimiento. En el caso de la convivencia no es tan sencilla su constatación si no ha sido llevada a cabo de forma notoria, puesto que las declaraciones de los futuros adoptantes o adoptandos no se consideran suficientes, pero ambos términos (acogimiento y convivencia) permiten establecer que cualquier situación de hecho, es decir, acogimiento legalmente constituido, guarda de hecho y guarda legal constituidas judicialmente, que hayan dado lugar a la convivencia ininterrumpida, podrían justificar tales adopciones. Vid., FELIú ReY: Comentarios a la Ley de Adopción, Tecnos, Madrid, 1989, pp. 119 y ss.; GutiéRRez SANTIAGO, op. cit., pp. 34 y ss., y 40; Alonso Crespo, op. cit., p. 88, y vid., CABALlero Gea: Matrimonio, Contrayentes del mismo o diferente sexo, Separación y Divorcio, Unión de hecho. Acogimiento y Adopción, Violencia de género, pensión impagada, Dykinson, Madrid, 2005, pp. 538 a 539.

${ }^{55} \mathrm{Vid}$., en este sentido, el Auto de la Audiencia Provincial de Madrid de 13 de enero de 1998, que niega la adopción de un mayor de edad, basándose en que la adopción de mayores de edad es excepcional y no puede aplicarse a supuestos no previstos, como sería el caso, en el sentido de que el adoptando padece una enfermedad que determina que su edad cronológica no corresponde con su edad mental, que conforme a los informes aportados correspondería a la de un niño de seis años, pudiéndose apreciar la convivencia iniciada antes de los catorce, la cual no existió, puesto que la convivencia entre aquéllos se inicio después de cumplir el adoptando diecinueve años de edad. En la misma línea se pronuncia el Auto de la Audiencia Provincial de Madrid de 4 de mayo de 1998, conforme al cual se niega la adopción, al no concurrir los datos susceptibles de excepción de la norma, siendo éstos que antes de la emancipación, la cual puede tener lugar por la mayoría de edad, hubiera existido una situación no interrumpida de acogimiento o convivencia en el seno familiar del adoptante, iniciada antes de que el adoptando hubiere cumplido los catorce años. 
ción tuvo lugar por concesión del titular de la patria potestad o judicial -la cual únicamente puede tener lugar cuando el menor haya cumplido los dieciséis años-, en la que será necesario que se acredite que el menor estuvo conviviendo con el adoptante antes de que cumpliera catorce años y que la situación de cohabitación se prolongó hasta que cumplió los dieciséis años y, de otra, aquélla en que la emancipación tuvo lugar por el matrimonio del menor con dispensa de edad, en la que solamente se exige esa cohabitación hasta el momento inmediatamente anterior al matrimonio, mientras que si no hubo dispensa, la relación debió iniciarse antes de los catorce años y prolongarse hasta el matrimonio del menor.

En cuanto a los supuestos concernientes a los mayores de edad, téngase presente que la fecha del cómputo se fija en la emancipación, por lo que si ésta no tuvo lugar, la relación debió existir antes de que el adoptando hubiese cumplido catorce años, y prolongarse hasta que cumpliera los dieciocho años.

Este carácter ininterrumpido de la cohabitación debe ser entendido de forma flexible, por su asimilación a la convivencia natural entre padres e hijos, en la que es posible y frecuente la separación física por razones educativas, laborales o por enfermedad, sin que suponga ello una ruptura de la continuidad.

Por otra parte, el Código civil no califica la convivencia ni exige que subsista en el momento de la adopción.

En este sentido, DíAZ-AMBronA ${ }^{56}$, -con acierto- dice que este hecho podría permitir la adopción de personas muy mayores en las que haya concurrido en su momento el requisito de la convivencia, de modo que sería necesario el establecimiento de una limitación de edad, al objeto de evitar tales adopciones.

Asimismo, en los supuestos de adopción de mayores de edad, el artículo 177 del Código civil, no concede el asentimiento o derecho de veto a los padres del adoptando, por lo que éstos no pueden hacer nada para evitarla, salvo si durante la minoría de edad del hijo no fueron privados de la patria potestad, y quedándoles en este caso únicamente el derecho de ser oídos, pero no podrán impedir la adopción de ninguna forma.

De modo que lógico sería equiparar estos casos a los de adopción

${ }^{56}$ Díaz-Ambrona BardaJí y Hernández GiL, Lecciones de Derecho..., 1999, op. cit., p. 375; Díaz-Ambrona Bardají y Hernández Gil, Lecciones de Derecho..., 2007, op. cit., p. 385. 
de menores de edad, en los que se otorga el derecho de veto o asentimiento con la posibilidad de privar del mismo en el supuesto de que incumplan sus deberes.

El párrafo anterior plantea la cuestión de si sería necesario el asentimiento de los padres en los casos en los que el adoptando estuviera emancipado conforme a lo establecido en el artículo 319 del Código civil, o estando sometido a la patria potestad prorrogada ${ }^{57}$, o rehabilitada ${ }^{58}$, se planteara la posibilidad de su adopción.

La respuesta a dicha cuestión se encuentra en función de la interpretación que se le dé al término "emancipado", que utilizan los artículos 175.2 y $177.2 .2^{\circ}$ del texto legal.

En este sentido, el primero de ellos prevé la adopción para los menores no emancipados y de forma excepcional para los que ya lo son, mientras que el segundo atribuye el derecho de asentimiento a los padres del adoptando que no se halle emancipado.

Por lo que conviene precisar que será necesario el asentimiento en los casos en los que persista la patria potestad, pues el asentimiento se asienta sobre la titularidad de la patria potestad, debiendo ser necesario desde que ésta nace hasta que finaliza por la emancipación o la mayoría de edad y decayendo si se demuestra en juicio contradictorio que están incursos en causa legal de privación de la misma por el incumplimiento de sus deberes paternos.

En relación al supuesto referido a la patria potestad prorrogada el artículo 171 del Código civil, dispone que: «La patria potestad sobre los hijos que hubieren sido incapacitados quedará prorrogada por ministerio de Ley, al llegar aquéllos a la mayor edad [...]». Por lo que, en este caso concreto, no permite que termine la patria potestad, sino que ordena su prórroga cuando el hijo cumple los dieciocho años.

Por su parte, la CE en su artículo 39.2, dice que: «los padres deben prestar asistencia de todo orden a los hijos habidos dentro o fuera del matrimonio, durante su minoría de edad, y en los demás casos en que legalmente proceda».

De modo que dentro de los demás casos en que legalmente proceda se incluirán a los hijos incapacitados o necesitados y, por tanto, la patria potestad hará referencia tanto a los menores de edad como a

${ }^{57}$ Fue declarado incapaz antes de cumplir los dieciocho años, pero en el momento actual ya es mayor de edad.

${ }^{58}$ Fue incapacitado con posterioridad a la mayoría de edad o de haber sido emancipado. 
los incapacitados. Luego si se les atribuye las mismas obligaciones respecto de ambos, se puede entender que también se les atribuirán a los padres los mismos derechos, por lo que el derecho a asentir o vetar la adopción quedaría inserto dentro de estos últimos.

Por otra parte, el artículo 171 del Código civil, se configura como la excepción del artículo $314.1^{\circ}$ del mismo texto legal, el cual establece: «La emancipación tiene lugar por la mayor edad», por lo que el menor adquiere la capacidad finalizando la patria potestad para él ${ }^{59}$, salvo que antes de ser emancipado por el cumplimiento de dicha edad, o de otra forma, sea declarado judicialmente incapaz. Supuesto en el que la patria potestad no finaliza, sino que continúa por «ministerio de la Ley» ${ }^{60} \mathrm{y}$, en consecuencia, tampoco tendría lugar la emancipación.

De forma que el derecho de asentimiento de los padres sería necesario en la amplitud marcada por el artículo $177.2 .2^{\circ}$, resultando posible la adopción de incapaces de cualquier edad, sin necesidad de que se cumplan los requisitos marcados en el artículo 175.2 del Código civil, puesto que no están emancipados.

En cuanto a los supuestos de patria potestad rehabilitada -es decir, aquélla que tendrá lugar cuando el hijo sea incapacitado después de cumplir los dieciocho años o después de haber sido emancipado de otra forma, debiendo convivir con los padres-, la necesidad del asentimiento de los padres tendrá la misma razón que en la prorrogada.

Punto en el que conviene precisar que el artículo 171 del Código civil, se refiere tanto a la patria potestad prorrogada como a la rehabilitada, debido a que establece la prórroga en cualquiera de estas dos formas.

Y en consonancia con lo anterior, al igual que ocurría en el caso de patria potestad prorrogada, el asentimiento de los padres será necesario, puesto que al continuar la patria potestad por ministerio de Ley no tendrá lugar la emancipación.

Finalmente, el supuesto previsto por el artículo 319 del Código civil no contempla una verdadera emancipación, ya que permite la revocación del consentimiento a la vida independiente, lo que implica que la patria potestad no se ha extinguido, pero sí se ha producido la suspensión de hecho de muchas de las facultades de la misma y, por tanto, la emancipación funciona mientras no se produzca la revoca-

${ }^{59}$ Cfr. Artículo $169.2^{\circ}$ Código civil.
${ }^{60}$ Cfr. Artículo 171 del Código civil. 
ción de la vida independiente, revocación que no se encuentra sujeta a requisito alguno.

Supuesto en el que los padres seguirán ostentando la titularidad de la patria potestad y estarán obligados a ejercerla en pro del hijo, debiendo revocar la vida independiente del hijo cuando le perjudique. De forma que los artículos 175.2 y 177.2.2 $2^{\circ}$ del Código civil no contemplan la emancipación por vida independiente del artículo 319 del mismo texto legal, para excluir el asentimiento paterno, porque esta titularidad no es verdadera, ya que no es definitiva.

\section{Sujetos que no pueden ser adoptados: las prohibiciones}

El artículo 175.3 del Código civil, dispone que: «No podrán adoptarse: $1^{\circ}$. A un descendiente. $2^{\circ}$. A un pariente en segundo grado de la línea colateral por consanguinidad. $3^{\circ}$. A un pupilo por su tutor hasta que haya sido aprobada definitivamente la cuenta general justificada de la tutela».

Del análisis del texto del precepto, se desprende la existencia de tres prohibiciones. Prohibiciones que se refieren tanto a la situación matrimonial como a la convivencia «more uxorio» ${ }^{61}$.

En relación a la primera prohibición, conviene precisar que ésta no distingue entre filiaciones ni tampoco entre grados de descendencia, por lo que, se refiere a todo descendiente y a cualquier tipo de descendiente, afectando a los descendientes inmediatos como sería el caso de los hijos o nietos y a los descendientes mediatos como sería el caso de los biznietos [...]. Además, también afectará no sólo a los descendientes matrimoniales, sino también a los no matrimoniales y a los adoptivos.

De conformidad con el texto del precepto, cabe entender que parece ser que solamente afecta a los descendientes por consanguinidad $\mathrm{y}$, por tanto, al no afectar a los descendientes por afinidad cabe la posibilidad de que el suegro/a pueda adoptar al yerno o a la nuera, ya que en estos casos no existe consanguinidad ${ }^{62}$.

La segunda prohibición, establece la imposibilidad de proceder a

${ }^{61}$ Vid., Díaz-Ambrona Bardají y Hernández Gil, Lecciones de Derecho..., 2007, op. cit., p. 386.

${ }^{62}$ Vid., en idéntico sentido, GARRIGA GoRINA: La adopción y el Derecho a conocer la filiación de origen. Un estudio legislativo y jurisprudencial, Aranzadi, Navarra, 2000, p. 29. 
la adopción de un pariente en segundo grado de la línea recta colateral por consanguinidad o afinidad, por lo que se prohíbe la adopción de un hermano por otro, ya sean de sangre o adoptivos, así como la adopción entre hermanos políticos o cuñados ${ }^{63}$.

La última prohibición se refiere a que el tutor no podrá adoptar al pupilo mientras no se haya aprobado definitivamente la cuenta de la tutela. Prohibición que la doctrina viene entendiendo que no existirá cuando no esté liquidada la cuenta, siempre indudablemente que esté aprobada ${ }^{64}$.

Esta prohibición tiene como objeto evitar fraudes al pupilo, protegiendo sus intereses y se justifica en el deber del tutor de rendir la cuenta general justificada de la tutela ${ }^{65}$, deber que podría intentar eludir al adoptar a su pupilo -asumiendo además mucho más poder de administración de los bienes de aquél y con menos control por parte de la autoridad judicial ${ }^{66}$ - de no existir tal prohibición, que desaparece desde el momento en que el Juez aprueba de forma definitiva la cuenta general justificada de la tutela ${ }^{67}$.

Por otra parte, al ser la tutela y la adopción incompatibles, será necesario para que el tutor pueda adoptar al pupilo que previamente se extinga aquélla, ya sea por alcanzar la mayoría o bien el beneficio de la mayor edad o por renuncia del tutor al cargo.

Asimismo, conviene precisar que esta prohibición no es impedimento para iniciar el expediente de adopción antes de la aprobación de la cuenta, al objeto de acumular al expediente adoptivo la resolución sobre la cuenta pendiente para acelerar los trámites de la adopción.

GARRIDO CHAMORRo, -con acierto-, dice que ésta debería ser la forma de proceder, ya que en caso contrario, cuando el adoptado estuviera bajo la tutela de su adoptante, sería necesario separar pre-

${ }^{63} \mathrm{Vid}$., Díaz-Ambrona BardaJí y Hernández Gil, añade que «con estas prohibiciones se pretende que no exista superposición de vínculos familiares; por ejemplo, que un nieto no sea al mismo tiempo hijo del abuelo, o que un hermano del cónyuge no sea al mismo tiempo hijo del otro cónyuge» (Lecciones de Derecho..., 2007, op. cit., p. 386).

${ }^{64}$ Vid., AlONSO CRESPO, op. cit., p. 78.

65 «Artículo 279. El tutor al cesar en sus funciones deberá rendir cuenta general justificada de su administración ante la Autoridad judicial [...]».

${ }^{66} \mathrm{Vid}$., Díaz-Ambrona Bardají y Hernández Gil, Lecciones de Derecho..., 2007, op. cit., p. 386.

${ }^{67}$ Vid., en este sentido, Lasarte Álvarez, op. cit., p. 333; Alonso Crespo, op. cit., p. 76; Quesada GonZÁlez, op. cit., p. 30. 
viamente a ese tutor del cargo para que rindiera la cuenta, nombrando a un nuevo tutor para el periodo de tramitación, y tras la rendición de la cuenta y bajo la nueva tutela, iniciar el trámite del expediente de la adopción, situación que resulta compleja. Además, añade que esta prohibición o impedimento es lógico que sólo afecte al tutor que deba rendir la cuenta y no al resto, es decir, que sólo será aplicable al tutor de los bienes y no al que lo sea de la persona ${ }^{68}$.

\section{LA IDONEIDAD Y EL PROCEDIMIENTO DE ADOPCIÓN: ENTIDADES PÚBLICAS DE ADOPCIÓN}

La idoneidad es la capacidad de la persona que la convierte en apta para adoptar y para ejercitar la patria potestad del menor. En este sentido, para que el adoptante pueda llevar a cabo la adopción, además de reunir los requisitos del artículo 175.1 del Código civil, será necesario que sea declarado idóneo por la entidad pública ${ }^{69}$ y posteriormente por el Juez.

En cuanto a las Entidades, éstas tendrán como finalidad primordial la de encargarse de la selección de los adoptantes, así como solicitar ante el juzgado la adopción para el menor. Salvo excepciones, tendrán la atribución exclusiva y excluyente para iniciar el expediente judicial de adopción, conferida por Ley, al objeto de evitar el tráfico de menores y asegurar la idoneidad de los nuevos padres.

El requisito, consistente en la idoneidad de los adoptantes ha sido introducido por la Ley Orgánica 1/1996, de 15 de enero, de Protección Jurídica del menor, de modificación parcial del Código civil y la Ley de Enjuiciamiento Civil, encontrándose en la actualidad recogido en el artículo 176.1 y 2 del Código civil.

${ }^{68}$ Vid., Garrido Chamorro, op. cit., p. 835. Vid., tambien, Lete del Río, op. cit, p. 490; AlONSO CRESPO, op. cit., 2004, p. 78; y, vid., QUESADA GONZÁLEZ, op. cit., p. 30.

${ }^{69}$ Dice la Disposición Adicional Primera de la Ley 21/1987, de 11 de noviembre, que «las entidades públicas mencionadas en esta Ley son los organismos del Estado, de las Comunidades Autónomas o de las Entidades Locales a las que, con arreglo a las leyes, corresponda, en el territorio respectivo, la protección de menores». "Las Comunidades Autónomas, en virtud de su competencia en materia de protección de menores, podrán habilitar, en su territorio, como instituciones colaboradoras de integración familiar, a aquellas Asociaciones o Fundaciones no lucrativas, constituidas conforme a las Leyes que sean aplicables, en cuyos estatutos o reglas figure como fin la protección de menores y siempre que dispongan de los medios materiales y equipos pluridisciplinares necesarios para el desarrollo de las funciones encomendadas». 
En otro orden de cosas, el Código civil no regula con detalle los requisitos necesarios para ser idóneas las personas que quieren adoptar, de modo que será necesario tener presente la normativa autonómica, debido a que ésta lo suele especificar.

No obstante, tal y como declara la CE en su artículo 149. 1. $6^{\circ 70} \mathrm{la}$ normativa de carácter procesal -referente a la competencia de los tribunales y a los procedimientos judiciales-, es competencia exclusiva del Estado y, por tanto, las CCAA deberán ajustarse a ella. Pero en materia de adopción la catalogación de las normas como sustantivas o procesales es difícil de establecer, por lo que algunas CCAA regulan ciertos aspectos, como la legitimación para iniciar el expediente ${ }^{71}$.

Los párrafos primero y segundo del artículo 176 del Código civil, disponen que: «1. La adopción se constituye por resolución judicial, que tendrá en cuenta siempre el interés del adoptando y la idoneidad del adoptante o adoptantes para el ejercicio de la patria potestad. 2. Para iniciar el expediente de adopción es necesaria la propuesta previa de la entidad pública a favor del adoptante o adoptantes que dicha entidad pública haya declarado idóneos para el ejercicio de la patria potestad. La declaración de idoneidad podrá ser previa a la propuesta. No obstante, no se requiere propuesta cuando en el adoptando concurra alguna de las circunstancias siguientes: $1^{\circ}$. Ser huérfano y pariente del adoptante en tercer grado por consanguinidad o afinidad. $2^{\circ}$. Ser hijo del consorte del adoptante. $3^{\circ}$. Llevar más de un año acogido legalmente bajo la medida de un acogimiento preadoptivo o haber estado bajo su tutela por el mismo tiempo. $4^{\circ}$. Ser mayor de edad o menor emancipado $»^{72}$.

En cuanto al primer párrafo del precepto, cabe decir que la adopción se constituirá por resolución judicial, en la que el Juez, tras la comprobación de la concurrencia de todos los requisitos legalmente

${ }^{70}$ «Artículo 149. -1. El Estado tiene competencia exclusiva sobre las siguientes materias. $6^{\circ}$. Legislación mercantil, penal y penitenciaria; legislación procesal, sin perjuicio de las necesarias especialidades que en este orden se deriven de las particularidades del derecho sustantivo de las Comunidades Autónomas».

${ }^{71}$ Este podría ser el caso de Cataluña que regula el artículo 235-38 en relación directa con los artículos 235-32 y 235-33 de la Ley 25/2010, de 29 de Julio, del Libro Segundo del Código civil de Cataluña, relativo a la Persona y la Familia, aunque en esencia lo hace igual que en el artículo 176 del Código civil para la legislación estatal.

${ }^{72}$ Vid., Gutiérrez Santiago, op. cit., pp. 59 y ss. Vid., también, Méndez Pérez: La adopción, Edit. Bosch, S. A., Barcelona, 2000, pp. 98 y ss.; PéREZ MARTín: Derecho de Familia, Adopcion, acogimiento, tutela y otras instituciones de protección de menores, Lex Nova, S.A., Valladolid, 2000, pp. 572 y ss. 
exigidos y atendiendo al interés del menor, deberá valorar si es conveniente para el adoptado. Pudiendo decidir -aunque concurran todos los requisitos establecidos por la Ley- su no constitución, cuando así lo estime oportuno en interés del menor.

En esta valoración de obligado cumplimiento, el Juez podrá ordenar la práctica de cuantas diligencias estime oportunas para asegurarse que la adopción resultará beneficiosa para el menor ${ }^{73}$. Además de oír a la Entidad pública, cuando el adoptando lleve más de un año acogido legalmente por aquél, al objeto de apreciar la idoneidad del adoptante ${ }^{74}$.

El párrafo segundo del artículo establece tanto la regla general, como las excepciones, no siendo necesaria en éstas últimas la intervención de la entidad pública, ya que determinadas personas gozan de una presunción «iuris tantum» de idoneidad, aunque el Juez deberá comprobarlo y pronunciarse de forma directa sobre la concurrencia o no de dicho presupuesto.

Por último, se puede decir que con anterioridad a efectuar la declaración de idoneidad, la entidad pública deberá comprobar que el solicitante cumple todos los requisitos, así como las aptitudes materiales y morales mínimas. Comprobación que se llevará a cabo por medio de un estudio psico-social y cuyos resultados deberán ser valorados por la entidad pública y, «si procede», emitirá un certificado de idoneidad a favor del adoptante o adoptantes. Certificado que acompañará a la propuesta de adopción que se deberá presentar en el Juzgado.

\section{REFLEXIONES CONCLUSIVAS}

En la actualidad, tras las numerosas reformas acaecidas en el Código civil, se puede afirmar que podrá ser adoptante una persona sola o dos personas, pudiendo ser la relación entre éstas consecuencia del matrimonio o de una unión de hecho estable «con independencia del sexo de sus integrantes». Cabe destacar que esta última expresión ha sido incorporada por la Ley 13/2005, de 1 de julio, por la que se modifica el Código civil en materia de derecho a contraer matrimonio. Expresión que es de suma importancia en esta materia, ya que al equiparar a las parejas heterosexuales las parejas homosexuales, hoy

\footnotetext{
${ }^{73}$ Cfr. Artículo 1.826 de la Ley de Enjuiciamiento Civil.

${ }^{74}$ Cfr. Artículo $177.3 .4^{\circ}$ del Código civil.
} 
REFLEXIONES SOBRE LOS REQUISITOS Y LAS PROHIBICIONES...

por hoy estas últimas también podrán proceder a formalizar la adopción, puesto que se encuentran incluidos dentro de la acepción «adoptantes».

Dos son los requisitos que deberán concurrir en el adoptante para proceder a la formalización de la adopción: De una parte, que los adoptantes tenga una edad mínima fijada en veinticinco años cumplidos, cediendo éste para uno de los adoptantes en caso de adopción conjunta, y no cediendo para el caso de adopción del hijo del cónyuge -al no tratarse de una adopción conjunta-, y de otra, que exista una diferencia de edad mínima -cifrada en catorce años- entre adoptando y adoptante, no contemplando este requisito excepción alguna.

Con la Ley 21/1987, de 11 de noviembre, de modificación del Código Civil y la Ley de Enjuiciamiento Civil en materia de adopción y otras formas de protección de menores, se suprime la exigencia de que el adoptante esté en pleno ejercicio de sus derechos civiles, de modo que podrán ser adoptantes tanto el incapaz como el menor emancipado, siempre y cuando reúnan los requisitos previstos por el Código civil. En este sentido, conviene puntualizar que en el primer supuesto será necesario que el incapaz, además de reunir dichos requisitos, tenga la capacidad necesaria para otorgar válidamente el consentimiento a la adopción. Mientras que en el segundo caso, necesariamente el menor emancipado deberá estar casado o formar una unión de hecho estable, debiendo su pareja o cónyuge tener veinticinco años de edad cumplidos, y presentar ambos una diferencia de edad mínima de catorce años respecto del adoptando.

El texto legal hace referencia tanto a la «adopción única» como a la «conjunta o sucesiva por ambos cónyuges», de modo que tras la formalización de la adopción el adoptando lo que completará es su filiación adoptiva. Por otra parte, se admite la adopción por una sola persona cuando la anterior adopción ya no exista, extinguiendo ésta a la primera adopción, con la excepción de que el segundo en adoptar sea el cónyuge o la pareja estable del adoptante fallecido o excluido, por lo que la adopción sucesiva lo que implica es la posibilidad de que un mismo adoptado pueda ser sujeto de distintas adopciones.

Asimismo, también prevé la posibilidad de que pueda constituirse válidamente una adopción cuando el adoptante hubiese fallecido. A este respecto, se establece una única exigencia, concretada en la prestación del consentimiento por el adoptante ante el Juez con anterioridad a su fallecimiento. Este supuesto es únicamente válido cuando se den en el adoptando determinadas circunstancias. 
Por otra parte, conviene destacar la excepcionalidad prevista por el artículo 175.2 del Código civil, al prever la posibilidad de adopción de los menores emancipados y de los mayores de edad siempre y cuando concurran determinadas circunstancias y cuando haya existido una relación de convivencia con el adoptante. Puesto que con carácter general se prevé la adopción de menores de edad, debido a que esta institución tiene como objeto principal la protección de los mismos.

Excepcionalidad que plantea como problema la exigencia de que la convivencia haya sido constante hasta el momento de la emancipación o de la mayoría de edad del adoptando, pero no exige su existencia en el momento de constituirse la adopción, lo que permite la posibilidad de adoptar personas que después de la emancipación o mayoría de edad dejaron de convivir con el adoptante. De modo que dentro de éstas podrían tener cabida "personas muy mayores» en las que en su momento sí concurrió el requisito de la convivencia, lo que podría originar que se formalizaran adopciones con fines fraudulentos.

El texto legal no prevé la adopción del «Nasciturus», toda vez que se regula en su articulado el asentimiento de la madre biológica, instaurando un plazo de reflexión concretado en treinta días desde el parto, al objeto de que la madre reflexione de forma detenida sobre la entrega o no del menor en adopción. Por lo que se prohíbe la constitución de la adopción durante dicho plazo -siendo su constitución, en caso de tener lugar, ilegal-, y en su caso, la otorgación del asentimiento se configurará como nulo de pleno derecho, por contradecir una norma de carácter imperativo.

En este sentido, se puede matizar que al no establecer el Código civil una edad mínima en el adoptando, podrían suscitarse dudas en relación al contenido establecido por el artículo 29 del texto legal, debido a que el concebido se tiene por nacido para todos los efectos que le sean favorables. Efectos que podrían incluir el de la adopción, dejando con ello el legislador una laguna legal sobre la posible adopción o no de estos sujetos. Por lo que la adopción del concebido, no se sabe hasta qué punto podría ser favorable, debido a que este supuesto, en la actualidad, es únicamente una posibilidad. Posibilidad que queda salvada con el párrafo cuarto del artículo $177.2 .2^{\circ}$, debido a que no puede iniciarse el procedimiento del menor hasta el nacimiento del mismo.

Con la Ley Orgánica 1/1996, de 15 de enero, de Protección Jurídica del menor, de modificación parcial del Código Civil y la ley de En- 
juiciamiento Civil, se introduce el requisito de la idoneidad de los adoptantes $^{75}$. Idoneidad que se configura como la aptitud de la persona que la hace apta para adoptar, ejercitando la patria potestad del menor. Esta idoneidad deberá ser declarada, en primer término, por la entidad pública - con la excepción de aquellos supuestos en los que no se requiere la intervención de ésta, ya que algunos sujetos gozan de una presunción «iuris tantum», de idoneidad, supuestos en los que será el propio Juez quien deba pronunciarse al respecto-, y con posterioridad, por el Juez.

Finalmente, estas entidades públicas desempeñan una función esencial en todo el procedimiento de adopción -debido a que, salvo excepciones, son las encargadas de seleccionar a los adoptantes y de solicitar ante el juzgado la adopción para el menor-, y conforme a la transferencia de competencias en materia de protección de menores y de asuntos sociales a las $\mathrm{CCAA}^{76}$, éstas son las que han elaborado leyes de carácter administrativo, al objeto de regular esta cuestión, designando a la entidad pública competente en esa materia en el respectivo territorio, y estableciendo los criterios de idoneidad de los adoptantes. Criterios que podrán variar de unas Comunidades a otras, cuando lo más lógico es que se determinaran sólo y exclusivamente por factores técnicos y que fueran comunes para todo el territorio español.

\section{BIBLIOGRAFÍA}

Alonso Crespo, Evelia, Adopción Nacional e Internacional, Panorámica procesal y sustantiva, incluida la intervención de los padres biológicos. Formularios. Anexos, La Ley, Madrid, 2004.

Caballero Gea, José Alfredo, Matrimonio, Contrayentes del mismo o diferente sexo, Separación y Divorcio, Unión de hecho. Acogimiento y Adopción, Violencia de género, pensión impagada, Dykinson, Madrid, 2005.

Cortada Cortina, Neus, «La adopción: presupuesto y requisitos legales», en Protección de menores, acogimiento y adopción, Santiago Espiau EsPiau y Antoni Vaquer Aloy (Eds.), Marcial Pons, Barcelona, 1999, pp. 147 a 162.

\footnotetext{
${ }^{75}$ Cfr. Artículo 176.1 y 2 del Código civil.

${ }^{76}$ Entre otras, se pueden mencionar las siguientes CCAA: Comunidad Valenciana, País Vasco, Aragón, Canarias, Cataluña ...
} 
Díaz-Ambrona BardaJí, $\mathrm{M}^{\mathrm{a}}$ Dolores y Hernández GiL, Francisco, Lecciones de Derecho de Familia, Centro de Estudios Ramón Areces, Madrid, 1999, 1. ${ }^{\mathrm{a}}$ ed.

-, Lecciones de Derecho de Familia, Centro de Estudios Ramón Areces, Madrid, 2007, 2. ${ }^{\text {a }}$ ed.

Feliú Rey, Manuel Ignacio, Comentarios a la Ley de Adopción, Tecnos, Madrid, 1989.

García CANTERo, Gabriel, «La adopción de mayores de edad», $A C$, Núm. 41, 1998, pp. 993 a 1007.

Garrido Chamorro, Pedro, Instituciones de Derecho Privado, IV, Familia, Vol. 2, coordinado por Juan Francisco Delgado DE Miguel, Civitas, Madrid, 2002.

GARRIGA GoRINA, Margarita, La adopción y el Derecho a conocer la filiación de origen. Un estudio legislativo y jurisprudencial, Aranzadi, Navarra, 2000.

GutiérRez Santiago, Pilar, Constitución de la adopción: Declaraciones relevantes, Cuadernos de Aranzadi Civil 7, Aranzadi editorial, Navarra, 2000.

Hualde Sánchez, José Javier, Comentarios a las reformas del Código Civil. Coordinado por Rodrigo Bercovitz y Rodríguez CANo, Tecnos, Madrid, 1993.

Lasarte Álvarez, Carlos, Principios de Derecho Civil IV, Derecho de Familia, Tomo. 6. ${ }^{\circ}$, Ed. Marcial Pons, Madrid, 2010, 9. ${ }^{\mathrm{a}}$ ed.

Lete Del Río, José Manuel, "Personas que pueden adoptar y ser adoptadas», $A C$, Núm. 5, febrero, 1991, pp. 75 a 90.

Méndez Pérez, José, La adopción, Edit. Bosch, S. A., Barcelona, 2000.

Peña Bernaldo de Quirós, Manuel, Derecho de Familia, Servicio de Publicaciones de la Universidad Complutense, Madrid, 1989.

Pérez Alvarez, Miguel Ángel, La nueva adopción, Civitas, Madrid, 1989.

Pérez Martín, Antonio Javier, Derecho de Familia, Adopcion, acogimiento, tutela y otras instituciones de protección de menores, Lex Nova, S.A., Valladolid, 2000.

Pous DE LA Flor, María Paz, «La adopción por las parejas de hecho", en Perspectivas del derecho de familia en el siglo XXI: XIII 
REFLEXIONES SOBRE LOS REQUISITOS Y LAS PROHIBICIONES...

Congreso Internacional de Derecho de Familia. Coordinado por Carlos Lasarte Alvarez, Araceli Donado Vara, María Fernanda Moretón SANz y Fátima YáÑez Vivero, Sevilla, 2004, pp. 39433968.

Quesada González, Ma Corona, La Adopción. Un estudio de sentencias, autos y resoluciones, Atelier, Barcelona, 2004.

VARGAS CABRERA, Bartolomé, «Régimen jurídico-sustantivo la adopción y funciones del Ministerio fiscal en la protección de Menores a la luz de la Ley Orgánica 1/96», en Protección Jurídica del Menor, Granada, 1997, pp. 84 a 102.

— «El acogimiento de menores. Concepto. Clases. Acogimiento judicial y administrativo. Cesación del acogimiento. La guarda de hecho», en Curso sobre Instituciones de protección de menores, Cuerpo de Secretarios Judiciales III, CEJAJ, Madrid, 1998, pp. 103 a 117.

\section{VI. ÍNDICE DE RESOLUCIONES ${ }^{77}$.}

\section{Tribunal Constitucional:}

$\underline{\text { Autos }}$

Auto de 14 de diciembre de 2004 (JUR: 2005\48725).

\section{Tribunal Supremo:}

STS de la Sala $1^{\text {a }}$ de lo Civil, de 21 de septiembre de 1999 (RJ: 1999\6944).

\section{Audiencias Provinciales:}

Sentencias

SAP de Barcelona, Sección 12, de 14 de febrero de 2001 (AC: 2005\405).

\section{$\underline{\text { Autos }}$}

AAP de Madrid, Sección 22, de 13 de enero de 1998 (AC: 1998\7).

AAP de Madrid, Sección 22, de 4 de mayo de 1998 (AC: 1998\732).

AAP de Badajoz, Sección 3, de 30 de junio de 2004 (JUR: 2004\192106).

77 Todas las sentencias y autos que has sido citados en este apartado, han sido mencionados a lo largo del trabajo. 


\section{Juzgado de Primera Instancia:}

Auto del Juzgado de $1^{\text {a }}$ Instancia Núm. 3 de Pamplona, de 22 de enero de 2004 (AC: 2004\164).

Auto del Juzgado de $1^{\text {a }}$ Instancia Núm. 2 de Gernika-Lumo Vizcaya, de 21 de febrero de 2005 (AC: 2005\365). 